\title{
UNILATERAL ABSENCE OF FIBULARIS TERTIUS: A CASE REPORT
}

Ankur Saxena', Shailendra Singh ${ }^{2}$, Anita Tuli ${ }^{3}$, Sashi Raheja ${ }^{4}$

\section{HOW TO CITE THIS ARTICLE:}

Ankur Saxena, Shailendra Singh, Anita Tuli, Sashi Raheja. "Unilateral Absence of Fibularis Tertius: A Case Report". Journal of Evolution of Medical and Dental Sciences 2014; Vol. 3, Issue 07, February 17;

Page: 1612-1614, DOI: $10.14260 /$ jemds/2014/2032

ABSTRACT: INTRODUCTION: Fibularis tertius (FT) was formerly called as the peroneus tertius ${ }^{1}$. FT muscle is a relatively small unipennate muscle found in the anterior compartment of the leg. It assists in dorsiflexion and eversion of foot ${ }^{2}$. The FT muscle originates from the distal third or more of the medial surface of fibula, the adjoining anterior surface of the interosseous membrane and the anterior crural intermuscular septum. Thereafter, tendon runs beneath the superior extensor retinaculum, inferior extensor retinaculum and gets inserted on the medial aspect of the dorsal surface of the base of the fifth metatarsal. FT muscle is supplied by the deep peroneal nerve(2,3, and 4$)$. FT has been described as a part of the extensor digitorum longus (EDL) muscle in classical textbooks².

CASE REPORT: During routine dissection for the first MBBS students, we observed that the peroneus tertius was absent on the dorsum of the Right lower limb of a 50 years old, donated embalmed male cadaver in the Department of Anatomy, Lady Hardinge Medical College, New Delhi, India. Both the limbs were carefully observed and examined to differentiate the absence of FT muscle. There was no scar mark or sign of injury on the limb. The other muscles of the compartment were present normally with their normal anatomical features. The photographs of the dorsum of the foot were taken for proper documentation and for ready reference. The absence of the peroneus tertius is very rare and not found in literature. Usually, the peroneus tertius is involved in dorsiflexion and eversion of the foot.

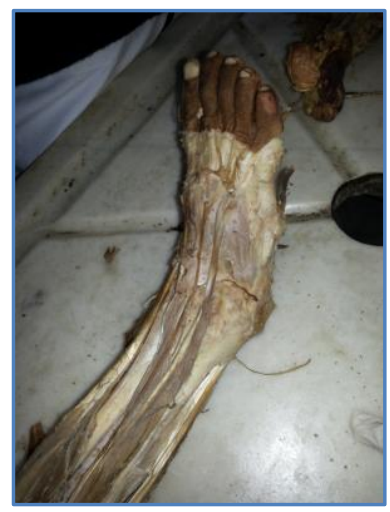

\section{Fig. 1 showing Extensor Hallucis tendon}

(1) \& Extensor Digitorum (2)

DISCUSSION: With the adaptation to erect posture, the foot had to not only bear the weight but also maintain the balance of body, while walking and standing on uneven surfaces. The Peroneus are the 
corner stone muscles that have evolved to perform this function. The FT muscle is absent in many primates with much variation in humans. ${ }^{5}$

Peroneus tertius is highly variable in its form and muscle bulk but is rarely completely absent. It may be attached to the fourth metatarsal rather than the fifth 6 . It may be as large as the Extensor Digitorum Longus or it may be absent. ${ }^{7}$ The muscle might remain rudimentary or even absent in 4.4$10 \%$ cases in humans. ${ }^{4}$ Similar study on Caucasian population showed its absence in $5-17 \%$ of cases studied. 8

FT has been described as a part of the extensor digitorum longus (EDL) muscle in classical textbooks. Although closely associated with the EDL, the FT is not a member of the superficial layer of digital extensors (EDL), and in reality, it is a proximally migrated part of the extensor digitorum brevis (EDB) of the little toe. ${ }^{8}$ It represents the extensor digiti minimi (proprius) (pedis) with its insertion displaced to the base of the fifth metatarsal. ${ }^{3}$

Peroneus Tertius may play a special proprioceptive role in sensing sudden inversion and then contracting reflexively to protect the anterior tibio-fibular ligament, the most commonly sprained ligament of the body. ${ }^{9}$

The clinical importance of the Peroneus Tertius concerning prevention and treatment of ankle ligament injuries is low. ${ }^{8}$

The insertion of the FT might play an important role in the causation of torsional stresses as observed in Jones fractures and stress fractures ${ }^{10}$. Foot surgeons might use the FT muscle flap for transposition and also for correcting any laxity in the ankle joint.11,4, and 12 The absence of FT may misguide the surgeons in performing graft and transplant surgeries. Hence radiological imaging techniques must be performed to confirm the existence of the FT before planning any operation in foot. Thus the bilateral presence or absence of the FT may have a clinical and phylogenetic viewpoint that is highlighted in this case report.

\section{REFERENCES:}

1. Rourke K., Dafydd H., Parkin I. G. Fibularis tertius: revisiting the Anatomy. Clin Anat. 2007; 20: 946-949.

2. McMinn R. M. H. Last's Anatomy: Regional and Applied. 9th Ed., Edinburgh: Churchill Livingstone; 1994: 188.

3. Bergman R. A., Thompson S. A., Afifi A. K., Saadeh F. A. Compendium of Human Anatomic Variations, Text, Atlas and World Literature. Baltimore \& Munich, Urban \& Schwarzenburg; 1988: 141.

4. Das S., Haji Suhaimi F., Abd Latiff A., Pa Pa Hlaing K., Abd Ghafar N., Othman F. Absence of the peroneus tertius muscle: cadaveric study with clinical considerations. Rom J Morphol Embryol. 2009; 50: 509-511.

5. Joshi S. D., Joshi S. S., Athavale S. A. Morphology of peroneus tertius muscle. Clin Anat. 2006; 19: 611-614.

6. Susan Standring. Gray's Anatomy, The Anatomical Basis of Clinical Practice. 39th Ed. London: Elsevier Churchill Livingstone; 2005: 1497.

7. Schaeffer J. Parsons. Morris' Human Anatomy, A complete systematic treatise. 12th Ed. New York: The Blakiston Division, McGraw Hill Book Company; 1966: 570-572. 
8. Witvrouw E., Borre K. V., Willems T. M., Huysmans, Bross E., De clercq D. The significance of Peroneus Tertius muscle in ankle injuries; a prospective study. Am J Sports Med. 2006; 34(7): 1159-1163.

9. Keith L. Moore. Clinical Oriented Anatomy. 6th Ed. India: Wolters Kluwer Pvt. Ltd. 2009: 589.

10. Vertullo C. J., Glisson R. R., Nunley J. A., Torsional strains in the proximal fifth metatarsal: implications for Jones and stress fracture management. Foot Ankle Int. 2004; 25(9): 650-656.

11. Arnold P. G., Yugueros P., Hanssen A. D. Muscle flaps in osteomyelitis of the lower extremity: a 20-year account. Plast Reconstr Surg. 1999; 104(1): 107-110.

12. Karlsson J., Wiger P. Longitudinal split of the peroneus brevis tendon and lateral ankle instability: treatment of concomitant lesions. J Athl Train, 2002; 37(4): 463-466.

\section{AUTHORS:}

1. Ankur Saxena

2. Shailendra Singh

3. Anita Tuli

4. Sashi Raheja

\section{PARTICULARS OF CONTRIBUTORS:}

1. Senior Resident, Department of Anatomy, Lady Hardinge Medical College, New Delhi.

2. Lecturer, Department of Anatomy, G.S.V.M. Medical College, Kanpur.

3. Director Professor, Department of Anatomy, Lady Hardinge Medical College, New Delhi.

4. Director Professor, Department of Anatomy, Lady Hardinge Medical College, New Delhi.

\section{NAME ADDRESS EMAIL ID OF THE} CORRESPONDING AUTHOR:

Dr. Ankur Saxena, Room No. 19, N.R.B,

Lady Hardinge Medical College Campus, Shaheed Bhagat Singh Marg,

(Opp. Shivaji Stadium), New Delhi -01.

E-mail: saar.ankur@gmail.com

Date of Submission: 30/12/2013.

Date of Peer Review: 31/12/2013.

Date of Acceptance: 30/01/2014.

Date of Publishing: 11/02/2014. 